\title{
Preference of Broiler Chicken for Different Light Colors in Relation to Age, Session of the Day and Behavior
}

\author{
Postgraduate Institute of Agriculture \\ University of Peradeniya \\ Sri Lanka
}

D. Senaratna ${ }^{*}$, T.S. Samarakone ${ }^{1}$, A.A.P. Madusanka ${ }^{2}$ and W.W.D.A. Gunawardane ${ }^{2}$

ABSTRACT. Preference (PR) of broilers (Cobb) for four different Light Colors (LC); red [RD], white [WT], green [GN] and blue [BL]; $5 \mathrm{~W}$ at 20 lux were tested on group level at 35 wks of age $(A G)$ in the morning $(M N)$, evening (EV) and night (NT) sessions of the day $(S D)$. Six replicates of 5 birds were each allowed to move freely between 4 compartments illuminated continuously with a $4 \mathrm{hr}$ light break. After one day of habituation to the test pen, location and behavior of birds were recorded once every $15 \mathrm{~min}$. over $18 \mathrm{hrs} /$ week. Twenty, mutually exclusive behaviors were assessed. Up to 21 days, no special PR was recorded. During the $3^{\text {rd }}$ week, significantly high $(p<0.05) P R$ was recorded $(29.42 \% \pm 7.07)$ in $R D$ while GN recorded the least (5.75\% $\% 6.98)$ in the NT. At $4^{\text {th }}$ week also the highest (33.33 $\% \pm 21.6)$ and the lowest $(9.44 \% \pm 13.35)$ PRs were recorded in $R D$ and $G N$, respectively. During 14-21 days, the highest eating [ET](18.34\% 10.99$)$ was recorded by BL, drinking $[D R](12.16 \% \pm 2.13)$ and scratching floor $[S F](4.9 \% \pm 5.5)$ by WT in the NT; walking (27.76 $\% \pm 25.25)$ and bird interaction [(BI] $(2.5 \% \pm 6.1)$ by $R D$ and $B L$, respectively in the $M N$;

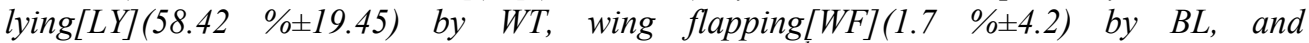
sleeping[SL](18.88\% \pm 21.5$)$ by RD in the EV. During $4^{\text {th }}$ week LC had an interaction effect (IE) with $S D$ on walking, dust bathing (DB), wing/leg stretching (WLS) and $S F$. LC and $S D$ separately had a significant $(p<0.05)$ effect on ET and $S L$ where DR only influenced by $L C$. At $5^{\text {th }}$ week only ET, DR, LY and DB had an IE while WF was only affected by $L C$. Above results have shown that certain behaviors changed with the $L C, A G, S D$ and their IE where standing and BI significantly decreased with the AG. These results support the notion that broilers prefer $R D L C$ in the NT under tropical environment. There sensitivity for LCs could be seen only after 21 days. RD and WT LCs are prefered more than the BL and GN. Associated Behaviors were significantly affected by the $L C, S D$ and $A G$.

Key words: Animal welfare, behavior, broiler, color preference, light

\section{INTRODUCTION}

Light is arguably the most important stimulus that the domestic fowl, Gallus gallus domesticus, receives from the physical environment (Perry \& Lewis, 1993). Its manipulation, whether through photoperiod, intensity, source or wavelength has profound effects upon the physiology and behavior of fowl (Manser, 1996). The fact that the fowl have preferences (PR) for different light environments has been shown by various researchers (Savory \&

Department of Animal Science, Faculty of Agriculture, University of Peradeniya, Peradeniya, Sri Lanka Department of Animal Science, Faculty of Agriculture, University of Ruhuna, Mapalana, Kamburupitiya, Sri Lanka

Author for correspondence: dsenaratna@yahoo.com 
Duncan 1982/83; Appleby et al., 1984; Alsam \& Wathes 1991; Widowski et al., 1992). In recent years, most research on the relationship between lighting and behavior in poultry has followed two approaches; PR tests and behavioural observations of broilers within their given light environment. The PR of poultry have been assessed for different light intensities (Davis et al., 1999), light sources (Widowski et al., 1992; Vandenberg \& Widowski, 2000), light colours (Prayitno \& Philips, 1997) and flickering frequencies (Widowski \& Duncan, 1996). In short, these studies have shown that hens prefer compact fluorescent to incandescent light sources (Widowski et al., 1992) and show no PR between compact fluorescent light sources of different flicker frequencies (Widowski \& Duncan, 1996) or between high-intensity high-pressure sodium over low-intensity incandescent lights (Vandenberg \& Widowski,2000). Broilers reared in white (WT), red (RD) or blue (BL) light (30 lux) during 7-28 days of life subsequently preferred BL light after $1 \mathrm{wk}$ of exposure, whilst birds reared in BL light preferred GN light after 1 week of exposure (Prayitno et al., 1997a). The above studies provide valuable information about the ability of domestic fowl to choose identical environments on the basis of light.

PR testing provides an important tool in animal welfare research and gives insight into what the animals want in a given situation. However, the social nature of broilers also causes birds in a group, thus, influencing choice of each other. Hence, testing the PRs of broiler chickens in a group will necessitate the use of more birds than testing them individually. The previous experience of an animal will probably affect its PRs. In poultry, the familiar resource is often preferred initially, although this PR may change with time and experience of other resources. It may therefore be important to ensure that all the resources are equally familiar to the broilers before enabling them to choose between them (Davis et al., 1999).

Although the beneficial production consequences of the broiler production systems are well known, little consideration has been given to the requirements of broilers for appropriate illuminance to perform particular behavior. Davis et al., (1999) showed that immature domestic fowl exhibits an apparent PR to perform certain behaviours in particular illuminances. Locating, selecting and manipulating food prior to ingestion is considered to be highly dependent upon vision, and previous studies have shown that fowl spend more time on eating [ET] (Savory \& Duncan 1982/83; Davis et al., 1999).

The aim of this investigation was to determine what PRs, if any, modern broilers show among a range of different light colours [LCs]; (Red [RD], white [WT], green [GN] and blue [BL]) on group basis, and whether such PRs are influenced by age [AG] (at 3 vs 5 wk), session of the day (SD) [morning (MN) vs. evening (EV) vs. night $(\mathrm{NT})$ ] and behavior. A better understanding of lighting PRs would help in the development of management practices and guidelines that are best suited to poultry welfare.

\section{MATERIALS AND METHODS}

\section{Animals and rearing environment}

A total of 30-d old broiler chicks of strain Cobb were used. Up to $14 \mathrm{~d}$, the chicks were brooded in a brooder guard under two, 40W normal incandescent light bulbs. Lighting was continuous at 60 lux intensity for the brooding period. Light intensity was measured by angling the cosine-corrected photoreceptor sensor of a light meter (Macam Photometer, Model L 103; Macam Photometrics Ltd. Livingston, UK) in the direction of maximum 
radiance at eye level of the bird ( $25 \mathrm{~cm}$ above the litter) according to the method defined by Tucker and Charles (1993).

\section{Preference test}

The experiment was conducted in six Foraging-Social Mazes (FSM) type experimental units (Fig 1) described by Schutz et al., (2002). Four identical, specially constructed mazes which were illuminated with four different LCs; RD, BL, GN and WT were used as one FSM which consisted of four, identical interconnecting compartments arranged in an annular form. Each compartment was rectangular in shape measuring $3 \mathrm{ft}$. long $\mathrm{x} 2 \mathrm{ft}$. wide $\mathrm{x} 3 \mathrm{ft}$. high, and one central box measuring $2 \times 2 \times 3 \mathrm{ft}^{3}$, arranged as in a plus maze. Central box facilitated access to the adjacent compartments. Each compartment was provided with a feeder and a bell shaped drinker to ensure ad libitum feed and water, and paddy husk was used as the litter material. Wire meshes were attached to the frame together with the black polythene that was just outside the arena. LCs were provided by using $5 \mathrm{~W}$ incandescent bulbs at 20 lux intensity.

Initially birds were coloured at different places on the body for easy identification. They were weighed and kept in the central box for 24 hours which was confined with a wire mesh (5 birds/ experimental unit). It was provided with a small bell shape drinker and a trough feeder. After 24 hrs of habituation, the feeder, drinker and the wire mesh were removed. Then birds were allowed to freely move according to their PR for the LCs. Artificial light was provided for $20 \mathrm{hrs}$ (from 10 p.m. to 6 p.m. of the following day) with a dark period (from 6 p.m. to 10 p.m.). Presence and behaviour were recorded at every $15 \mathrm{~min}$. for consecutive 2 hours during MN (9-11a.m.), EV (2-4 p.m.) and NT (10 p.m.-12 midnight). Four visits/hour/experimental unit were made using scan sampling method (Martin \& Bateson, 1993). Behaviour of the birds under different LCs was studied using an ethogarm. At $35 \mathrm{~d}$, birds were weighed individually and humanely slaughtered them at $36 \mathrm{~d}$ of their age. Simultaneously the presence under respective LC with the behaviour of five birds was evaluated in each of the FS.

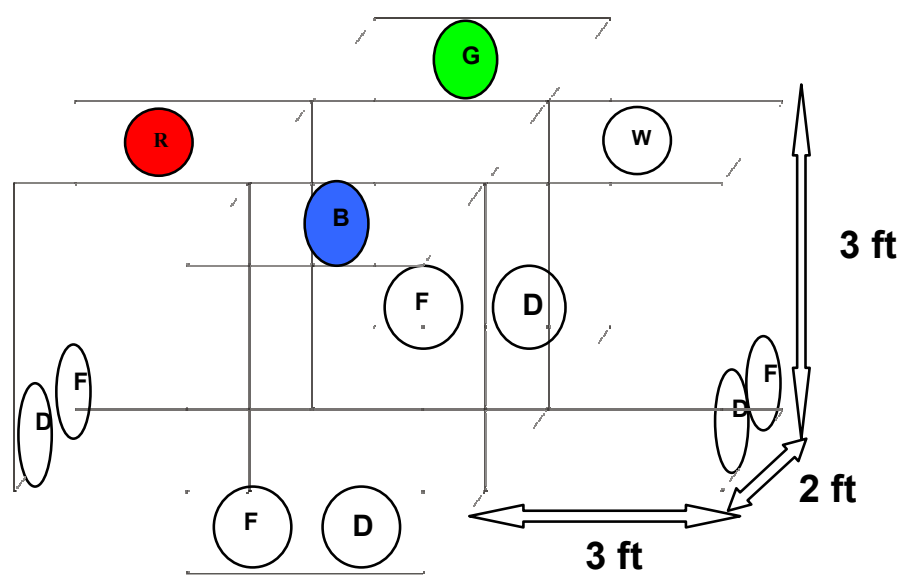

Fig. 1. Experimental design

Light sources: R-Red, B-Blue, G-Green,W-White

F-Feeder, D-Drinker 


\section{Statistical analysis}

The total presence in the four light environments by 6 blocks (replicates) and respective behaviours were analysed by ANOVA, using the Statistical Analysis Software (SAS, SAS Institute Inc. Release 9.1). The difference between treatment means was examined by including treatment, $\mathrm{AG}, \mathrm{SD}$ as main effects and all two way interactions. Effect of the AG was compared by adopting pooled t-test using SPSS package.

\section{RESULTS AND DISCUSSION}

\section{Total occupancy}

Results of this investigation indicate that broiler chicks of commercial strain of Cobb shows significant PRs when allowed to choose among a range of different LCs. The total percentage time spent in particular LCs at different SD is shown by Table 1.

Table 1. Significant effect of AG, SD and LC on the presence in particular LC (Data taken from ANOVA, $n=90$ ) not significant $=n s p>0.05$; significant $p<0.05$ )

\begin{tabular}{|c|c|c|c|c|c|c|}
\hline \multirow[t]{2}{*}{ Age/Session } & \multicolumn{5}{|c|}{ Presence in different light colours (\%) } & \multirow[t]{2}{*}{$p$} \\
\hline & Red & White & Green & Blue & No light & \\
\hline \multicolumn{7}{|l|}{$14-21 d$} \\
\hline \multirow[t]{2}{*}{$\mathrm{M}$} & $19.31^{\mathrm{a}} \pm 28.71$ & $21.11^{\mathrm{a}}$ & $23.06^{\mathrm{a}}$ & $17.92^{\mathrm{a}}$ & $22.09^{\mathrm{a}}$ & ns \\
\hline & & \pm 17.59 & \pm 17.75 & \pm 16.07 & \pm 9.38 & \\
\hline \multirow[t]{2}{*}{$\mathrm{E}$} & $14.99^{\mathrm{a}} \pm 19.30$ & & & & & ns \\
\hline & & $19.03^{\mathrm{a}}$ & $12.64^{\mathrm{a}}$ & $27.92^{\mathrm{a}}$ & $22.36^{\mathrm{a}}$ & \\
\hline $\mathrm{N}$ & $24.59^{\mathrm{a}} \pm 9.29$ & \pm 21.03 & \pm 9.52 & \pm 28.93 & \pm 10.54 & $\mathrm{~ns}$ \\
\hline \multirow[t]{2}{*}{$22-28 \mathrm{~d}$} & & $25.69^{\mathrm{a}}$ & $5.56^{\mathrm{a}} \pm 8.62$ & $24.58^{\mathrm{a}}$ & $20.00^{\mathrm{a}}$ & \\
\hline & & \pm 15.38 & & \pm 15.57 & \pm 13.91 & \\
\hline M & $22.25^{\mathrm{a}} \pm 10.61$ & & & & & ns \\
\hline \multirow[t]{2}{*}{$\mathrm{E}$} & $15.92^{\mathrm{a}} \pm 25.91$ & & $14.42^{\mathrm{a}}$ & & & ns \\
\hline & & $17.42^{\mathrm{a}}$ & \pm 7.07 & $15.25^{\mathrm{a}}$ & $30.17^{\mathrm{a}}$ & \\
\hline \multirow[t]{2}{*}{$\mathrm{N}$} & $29.42^{a, b} \pm 7.07$ & \pm 6.95 & $18.50^{\mathrm{a}}$ & \pm 6.77 & \pm 4.06 & 0.027 \\
\hline & & $\begin{array}{l}33.92^{\mathrm{a}} \\
\pm 25.85\end{array}$ & \pm 15.18 & $\begin{array}{l}15.46^{\mathrm{a}} \\
\pm 8.94\end{array}$ & $\begin{array}{l}16.08^{\mathrm{a}} \\
\pm 7.08\end{array}$ & \\
\hline \multirow[t]{2}{*}{$28-35 d$} & & & $5.75^{\mathrm{c}} \pm 6.98$ & & & \\
\hline & & $15.92^{\mathrm{a}, \mathrm{b}}$ & & $12.35^{\mathrm{b}, \mathrm{c}}$ & $34.92^{\mathrm{a}}$ & \\
\hline M & $21.53^{\mathrm{a}} \pm 11.46$ & \pm 12.85 & & \pm 5.62 & \pm 8.28 & $\mathrm{~ns}$ \\
\hline $\mathrm{E}$ & $16.67^{\mathrm{a}} \pm 23.58$ & & & & & ns \\
\hline \multirow[t]{6}{*}{$\mathrm{N}$} & $33.33^{\mathrm{a}} \pm 21.60$ & & $\begin{array}{l}11.94^{\mathrm{a}} \\
\pm 3.89\end{array}$ & & & ns \\
\hline & & $17.50^{\mathrm{a}}$ & & $23.06^{\mathrm{a}}$ & $24.44^{\mathrm{a}}$ & \\
\hline & & \pm 13.01 & $\begin{array}{l}14.48^{\mathrm{a}} \\
\pm 21.33\end{array}$ & \pm 18.41 & \pm 07.20 & \\
\hline & & $32.92^{\mathrm{a}}$ & & $27.15^{\mathrm{a}}$ & $08.01^{\mathrm{a}}$ & \\
\hline & & \pm 32.72 & $\begin{array}{l}9.44^{\mathrm{a}} \\
\pm 13.35\end{array}$ & \pm 18.45 & \pm 05.59 & \\
\hline & & $\begin{array}{l}16.70^{\mathrm{a}} \\
\pm 8.32\end{array}$ & & $\begin{array}{l}10.42^{\mathrm{a}} \\
\pm 12.02\end{array}$ & $23.12^{\mathrm{a}} \pm 10$ & \\
\hline
\end{tabular}

$\mathrm{M}=$ morning; $\mathrm{E}=$ evening; $\mathrm{N}=$ night 
Up to $21 \mathrm{~d}$, there was no special PR for any LC. At the $4^{\text {th }}$ week LC PR was dependent on the SD where the highest PR was recorded for RD and the lowest PR was recorded in GN. Senaratna et al. (2010) also found that LC PR of broilers is significantly affected by the AG of the birds and the SD on an individual animal basis under same management and environmental conditions. This apparent reversal of overall PR was mainly due to changes associated with the 8 activities, i.e. drinking (DR), walking (WK), standing (ST), lying (LY), litter eating (LE), bird interaction (BI), scratching floor (SF) and dozing (DZ) [Table 5].

Davies et al. (1999) and Kristensen et al. (2006) used groups of broiler chickens whereby given a choice of four different, equally familiar light environments [for light intensities, Davies et al. (1999) and for light colours, Kristensen et al. (2006)] over a period of 6-10 d at two ages (1-2 and 5-6 wk). In both experiments, the broilers chose differently at the two AGs, suggesting a shift in PR for both light intensity and LC between the beginning and the end of the growing period. Reviewed literature showed that the birds' eye development takes place with the AG thereby showing a sensitivity or a PR for a special colour. Up to $5^{\text {th }}$ week still marked the highest PR for RD but no significant difference was recorded with the other LCs. The reason may be during this week there was an unusual cool climatic condition prevailed (average $\mathrm{T}^{\circ}=23.5^{\circ} \mathrm{C}$, according to meteorological records for Mapalana) which affects the flock cuddling together over the effect of LC. Kristensen et al., 2006 also mentioned after two experiments that broilers have a PR for certain light sources at six weeks, but not at 1 week of AG. There may be several reasons for the lack of light PR in 1 wk-old broiler chickens. It could be argued that in the wild, young chicks would be led by the hen and hence may not yet possess the ability to choose actively between light environments. Neurobiological studies have shown that one week old chicks have not completed the neural development of the visual cortex (Rogers, 1994) and young chicks show AG-dependent lateral asymmetry in response to visual stimuli (Regolin \& Vallortigara, 1996). However, a PR for visual complexity has been shown as early as in 5-6 d old chicks (Berryman et al., 1971).

\section{Associations between light colours and behavior}

Both LC and SD influenced the behavior of domestic fowl (Table 2, 3 and 4). Some of the defined 17 behavioural categories were observed to be significantly depend on the LC, SD and the AG of the birds. During 14-21 d, the highest values were recorded for ET $(18.34 \pm 10.99 \%)$ by BL, DR $(12.16 \pm 2.13 \%)$ and SF $(4.9 \pm 5.5 \%)$ by WT in the NT, WK $(27.76 \pm 25.25 \%)$ and $\mathrm{BI}(2.5 \pm 6.1 \%)$ by $\mathrm{RD}$ and $\mathrm{BL}$ respectively in the MN, LY $(58.42 \pm 19.45 \%)$ by WT, WF $(1.7 \pm 4.2 \%)$ by BL and SL $(18.88 \pm 21.5 \%)$ by RD in the EV (Fig. 2). It was also found that exposure to light stimulus is known to induce behavioural arousal (movement) and desynchronization of the electroencephalogram (physiological arousal) in rats (Sakai et al., 1996). 
Table 2. Effect of LC and SD on the presence (14-35 d) and behavior during 14-21 d

\begin{tabular}{lccc}
\hline Presence/behaviour & $\begin{array}{c}\text { Time period/Session } \\
\text { (S) }\end{array}$ & $\begin{array}{c}\text { Light colour } \\
(\mathbf{C})\end{array}$ & $\begin{array}{c}\text { Interaction } \\
\text { (CxS) }\end{array}$ \\
\hline Presence & & & \\
$14-21 \mathrm{~d}$ & $\mathrm{~ns}$ & $\mathrm{~ns}$ & $\mathrm{~ns}$ \\
$22-28 \mathrm{~d}$ & $\mathrm{~ns}$ & $\mathrm{~ns}$ & $* *$ \\
$29-35 \mathrm{~d}$ & $\mathrm{~ns}$ & $* * *$ & $\mathrm{~ns}$ \\
Eating & $* * *$ & $* *$ & $* * *$ \\
Drinking & $\mathrm{ns}$ & $* * *$ & $* *$ \\
Walking & $\mathrm{ns}$ & $\mathrm{ns}$ & $* *$ \\
Standing & $\mathrm{ns}$ & $\mathrm{ns}$ & $\mathrm{ns}$ \\
Preening & $\mathrm{ns}$ & $* * *$ & $* *$ \\
Lying & $* *$ & $\mathrm{~ns}$ & $* *$ \\
Litter Eating & $* *$ & $\mathrm{~ns}$ & $\mathrm{~ns}$ \\
Dust Bathing & $\mathrm{ns}$ & $* *$ & $\mathrm{~ns}$ \\
Bird Interaction & $* *$ & $* *$ & $* * *$ \\
Wing Flapping & $\mathrm{ns}$ & $\mathrm{ns}$ & $\mathrm{ns}$ \\
Vocalization & $\mathrm{ns}$ & $* *$ & $\mathrm{~ns}$ \\
Wing/Leg & $\mathrm{ns}$ & $\mathrm{ns}$ & $\mathrm{ns}$ \\
Stretching & $* * *$ & $\mathrm{~ns}$ & $\mathrm{~ns}$ \\
Sleeping & $\mathrm{ns}$ & $\mathrm{ns}$ & $* *$ \\
Scratching Floor & $* * *$ & $\mathrm{~ns}$ & $\mathrm{~ns}$ \\
Dozing & $\mathrm{ns}$ & $\mathrm{ns}$ & $\mathrm{n} / \mathrm{a}$ \\
Idling & $\mathrm{ns}$ & & $\mathrm{ns}$ \\
Other & & & \\
\hline
\end{tabular}

$* * \mathrm{p}<0.01 ; * * * \mathrm{p}<0.001 ;$ ns not significant $=\mathrm{p}>0.05 ; \mathrm{n} / \mathrm{a}$-not applicable

During $3^{\text {rd }}$ and $5^{\text {th }}$ weeks, there was no significant interaction with SD for the presence under respective LC. However, during $4^{\text {th }}$ week, LC showed a significant interaction with the SD (Table 2). In addition ET, DR, WK, Preening (PRE), LY, BI and SF behaviours showed an interaction with the time and the LC.

Laying hens showed more PRE behavior in compact fluorescent light than incandescent light (Widowski et al., 1992) and performed more nesting, PRE, ground pecking and DR in high pressure sodium light of high intensity than in incandescent light of low intensity (Vandenberg \& Widowski, 2000)

During $4^{\text {th }}$ week LC had an interactive effect with the SD on WK, DB, WLS and SF behaviours (Table 3). Though there was no interaction effect on ET and SL behaviours, LC and the SD separately had a significant effect on them while DR had only influenced by the LC. During $5^{\text {th }}$ week, ET, DR, LY and DB behaviours showed an interaction effect among LC and SD (Table 4). WF only affected by LC. WK, PRE, LE, SL, DZ and other behaviours only affected by the SD. Above results show that the interaction effect on certain behaviours vary with the $\mathrm{AG}$ of the birds (Table 5). 
Table 3. Effect of LC and the SD upon the behavior during 22-28 d

\begin{tabular}{lccc}
\hline Behaviour & $\begin{array}{c}\text { Time period/session } \\
\text { (SD) }\end{array}$ & $\begin{array}{c}\text { Light colour } \\
(\mathbf{C})\end{array}$ & $\begin{array}{c}\text { Interaction } \\
\text { (CxS) }\end{array}$ \\
\hline Eating & $* * *$ & $* * *$ & $\mathrm{~ns}$ \\
Drinking & $\mathrm{ns}$ & $* * *$ & $\mathrm{~ns}$ \\
Walking & $\mathrm{ns}$ & $\mathrm{ns}$ & $* *$ \\
Standing & $\mathrm{ns}$ & $\mathrm{ns}$ & $\mathrm{ns}$ \\
Preening & $* *$ & $\mathrm{~ns}$ & $\mathrm{~ns}$ \\
Lying & $\mathrm{ns}$ & $\mathrm{ns}$ & $\mathrm{ns}$ \\
Litter eating & $* * *$ & $\mathrm{~ns}$ & $\mathrm{~ns}$ \\
Dust bathing & $* *$ & $* * *$ & $* *$ \\
Bird interaction & $\mathrm{ns}$ & $\mathrm{ns}$ & $\mathrm{ns}$ \\
Wing flapping & $\mathrm{ns}$ & $\mathrm{ns}$ & $\mathrm{ns}$ \\
Vocalization & $\mathrm{ns}$ & $\mathrm{ns}$ & $\mathrm{n} / \mathrm{a}$ \\
Wing/leg stretching & $* *$ & $* *$ & $* * *$ \\
Sleeping & $* *$ & $* * *$ & $\mathrm{~ns}$ \\
Scratching floor & $* *$ & $* *$ & $* *$ \\
Dozing & $* * *$ & $\mathrm{~ns}$ & $\mathrm{~ns}$ \\
Idling & $\mathrm{ns}$ & $\mathrm{ns}$ & $\mathrm{ns}$ \\
Other & $\mathrm{ns}$ & $\mathrm{ns}$ & $\mathrm{ns}$ \\
\hline
\end{tabular}

$* * \mathrm{p}<0.01 ; * * * \mathrm{p}<0.001 ;$ not significant $=\mathrm{ns} \mathrm{p}>0.05 ; \mathrm{n} / \mathrm{a}-$ not applicable

Table 4. Effect of LC and SD upon the behavior during 29-35 d

\begin{tabular}{lccc}
\hline Behaviour & $\begin{array}{c}\text { Time period/session } \\
\text { ( S) }\end{array}$ & $\begin{array}{c}\text { Light colour } \\
(\mathbf{C})\end{array}$ & $\begin{array}{c}\text { Interaction } \\
\text { (CXS) }\end{array}$ \\
\hline Eating & $* * *$ & $* * *$ & $* *$ \\
Drinking & $\mathrm{ns}$ & $* * *$ & $* *$ \\
Walking & $* *$ & $\mathrm{~ns}$ & $\mathrm{~ns}$ \\
Standing & $\mathrm{ns}$ & $\mathrm{ns}$ & $\mathrm{ns}$ \\
Preening & $* *$ & $\mathrm{~ns}$ & $\mathrm{~ns}$ \\
Lying & $* * *$ & $* * *$ & $* *$ \\
Litter eating & $* *$ & $\mathrm{~ns}$ & $\mathrm{~ns}$ \\
Dust bathing & $* *$ & $* * *$ & $* * *$ \\
Bird interaction & $\mathrm{n} / \mathrm{a}$ & $\mathrm{n} / \mathrm{a}$ & $\mathrm{n} / \mathrm{a}$ \\
Wing flapping & $\mathrm{ns}$ & $* * *$ & $\mathrm{~ns}$ \\
Vocalization & $\mathrm{ns}$ & $\mathrm{ns}$ & $\mathrm{ns}$ \\
Wing/leg stretching & $\mathrm{ns}$ & $\mathrm{ns}$ & $\mathrm{ns}$ \\
Sleeping & $* * *$ & $\mathrm{~ns}$ & $\mathrm{~ns}$ \\
Scratching floor & $\mathrm{ns}$ & $\mathrm{ns}$ & $\mathrm{ns}$ \\
Dozing & $* * *$ & $\mathrm{~ns}$ & $\mathrm{~ns}$ \\
Idling & $\mathrm{ns}$ & $\mathrm{ns}$ & $\mathrm{ns}$ \\
Other & $* *$ & $\mathrm{~ns}$ & $\mathrm{~ns}$ \\
\hline
\end{tabular}

$* * \mathrm{p}<0.01 ; * * \mathrm{p}<0.001 ;$ not significant $=\mathrm{ns} \mathrm{p}>0.05 ; \mathrm{n} / \mathrm{a}-\mathrm{not}$ applicable 
Table 5. Mean $( \pm$ SD) proportion of time (percentage) spent in different behaviours at 3- 5 weeks

\begin{tabular}{lllllll}
\hline $\begin{array}{l}\text { Presence/ } \\
\text { behaviour }\end{array}$ & $\mathbf{3}^{\text {rd }}$ week vs. $\mathbf{4}^{\text {th }}$ week & $\mathbf{P}^{\mathbf{1}}$ & $\mathbf{4}^{\text {th }}$ week & vs. $\mathbf{5}^{\text {th }}$ week & $\mathbf{P}^{\mathbf{2}}$ \\
\hline Presence & $20.06 \pm 5.67$ & $19.85 \pm 8.5$ & 0.94 & $18.95 \pm 9.4$ & $19.38 \pm 8.03$ & 0.89 \\
Eating & $7.75 \pm 7.15$ & $9.88 \pm 7.28$ & 0.43 & $9.57 \pm 7.44$ & $12.72 \pm 9.5$ & 0.32 \\
Drinking & $3.69 \pm 3.31$ & $6.85 \pm 4.75$ & 0.04 & $6.32 \pm 4.59$ & $5.78 \pm 4.24$ & 0.74 \\
Walking & $6.11 \pm 6.48$ & $2.35 \pm 2.35$ & 0.04 & $2.49 \pm 2.39$ & $2.33 \pm 1.85$ & 0.83 \\
Standing & $7.21 \pm 3.99$ & $4.90 \pm 4.75$ & 0.16 & $4.94 \pm 4.74$ & $2.39 \pm 1.99$ & 0.05 \\
Preening & $7.17 \pm 3.49$ & $6.67 \pm 3.92$ & 0.71 & $6.47 \pm 3.98$ & $6.49 \pm 3.12$ & 0.98 \\
Lying & $39.07 \pm 16.41$ & $50.37 \pm 9.2$ & 0.03 & $47.29 \pm 15.14$ & $44.71 \pm 12.38$ & 0.61 \\
Litter eating & $4.99 \pm 2.89$ & $2.22 \pm 1.69$ & 0.03 & $2.28 \pm 1.73$ & $2.45 \pm 1.77$ & 0.78 \\
Dust bathing & $0.89 \pm 1.43$ & $0.77 \pm 1.62$ & 0.82 & $1.02 \pm 1.81$ & $1.25 \pm 3.07$ & 0.80 \\
Bird & $0.91 \pm 1.89$ & $0.73 \pm 1.13$ & 0.76 & $0.99 \pm 1.39$ & $0.00 \pm 0.00$ & 0.01 \\
interaction & & & & & & \\
Wing & $0.66 \pm 0.93$ & $0.51 \pm 0.57$ & 0.61 & $0.77 \pm 1.05$ & $0.22 \pm 0.42$ & 0.07 \\
Flapping & & & & & & \\
Vocalization & $1.87 \pm 7.23$ & $0.00 \pm 0.00$ & 0.33 & $0.27 \pm 1.03$ & $1.00 \pm 3.87$ & 0.34 \\
Wing/leg & $1.36 \pm 1.41$ & $1.02 \pm 1.29$ & 0.49 & $1.26 \pm 1.48$ & $1.07 \pm 1.16$ & 0.69 \\
stretching & & & & & & \\
Sleeping & $6.17 \pm 5.89$ & $8.83 \pm 6.80$ & 0.26 & $8.33 \pm 6.86$ & $5.17 \pm 4.86$ & 0.61 \\
Scratching & $1.25 \pm 1.51$ & $0.11 \pm 0.43$ & 0.01 & $0.37 \pm 1.09$ & $1.73 \pm 6.71$ & 0.21 \\
floor & & & & & & \\
Dozing & $0.78 \pm 0.86$ & $3.39 \pm 3.51$ & 0.01 & $3.61 \pm 3.4$ & $2.74 \pm 2.69$ & 0.44 \\
Idling & $0.00 \pm 0.00$ & $4.46 \pm 0.17$ & 0.33 & $0.90 \pm 1.10$ & $9.93 \pm 0.26$ & 0.45 \\
Other & $1.21 \pm 1.94$ & $0.68 \pm 0.69$ & 0.33 & $0.31 \pm 1.03$ & $1.34 \pm 1.79$ & 0.43 \\
\hline
\end{tabular}

$\mathrm{P}^{1,2} \mathrm{p}$ value from pooled $\mathrm{t}$-test $(\mathrm{n}=15)$

Though DR, WK, LY, LE, SF and DZ behaviours significantly different between $3^{\text {rd }}$ and $4^{\text {th }}$ weeks, that effect could not be seen between $4^{\text {th }}$ and $5^{\text {th }}$ weeks. Similarly, ST and BI behaviours were significantly different between $4^{\text {th }}$ and $5^{\text {th }}$ weeks, and were not significant during $3^{\text {rd }}$ and $4^{\text {th }}$ weeks. ST and BI behaviors significantly decreased with the AG.

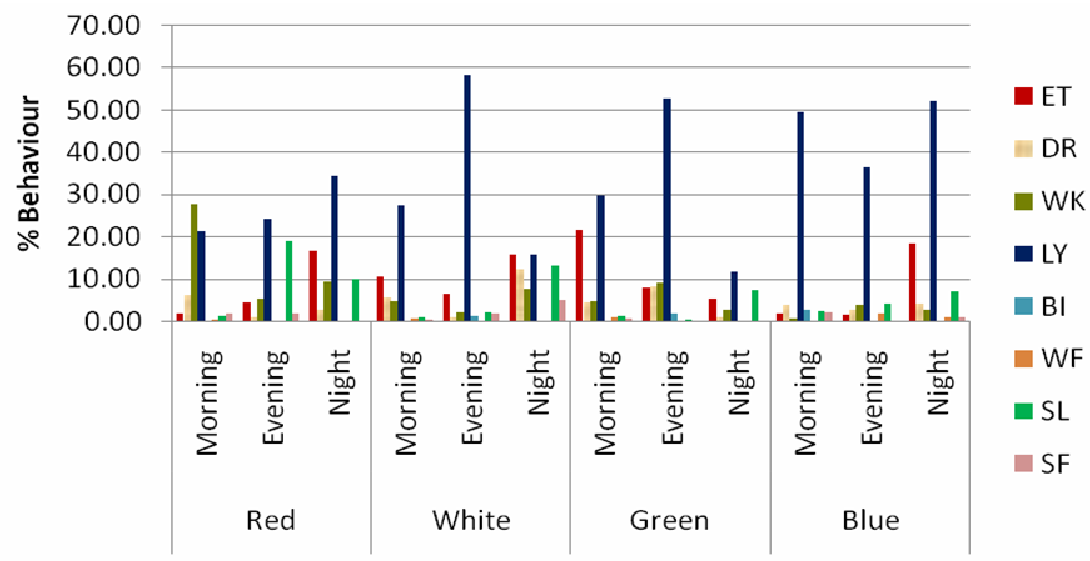

Fig. 2 Significantly different $(p<0.05)$ behaviors among different LC environments during 14-21days 
During 22-28 d (Fig.3), certain behaviours showed significant difference $(\mathrm{p}<0.05)$ where the highest ET $(25.41 \pm 13 \%)$ and SL $(12.17 \pm 12.8 \%)$ behaviours were recorded by WT in the NT. Birds were more active in RD which was proved by the highest DB $(1.68 \pm 2.5 \%)$ and WLS $(2.14 \pm 4.0 \%)$ performed by RD in the MN. Under GN also WLS showed the same results $(2.14 \pm 4.0 \%)$ in the NT (Fig.3). Early findings also proved that broiler birds were more active in RD (more ground pecking, wing stretching and aggression) and WT light (more WK) than in GN or BL light of 30 lux between 7 and 28 days of AG. Bright RD light increased WK, feeding and stretching behavior (Prayitno et al., 1997). Davis et al., (1999) found that broilers spent more time DR, performing litter-directed behavior and feeding in bright light (2001 ux), whereas Vandenberg and Widowski (2000) found more feeding behavior in incandescent light of low-intensity. LY behaviour was not influenced by LC in this study. Kristensen et al., (2006) also found that sitting behaviour was not influenced by light source or intensity.

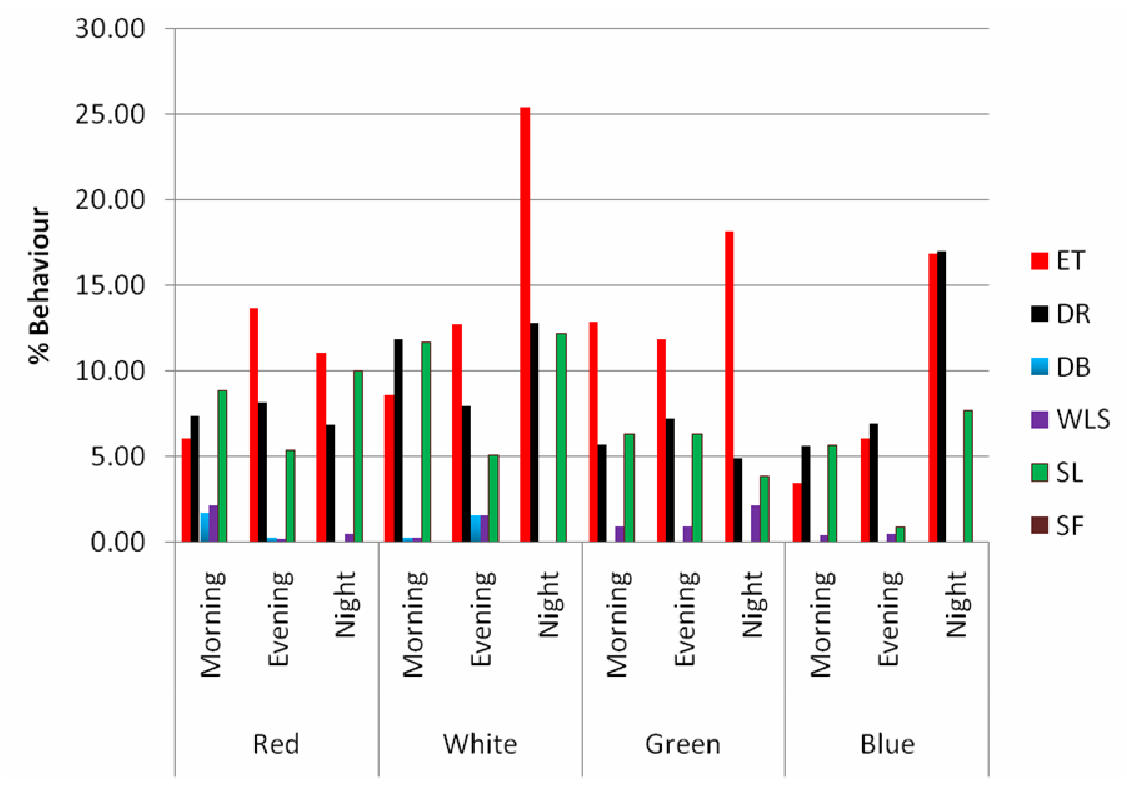

Fig. 3. Significantly different $(p<0.05)$ behaviours among different LC environments during 22-28d

During 29-35 d (Fig. 4) the highest ET and DR behaviours were shown by RD and BL, respectively in the EV whereas the highest DB, WLS, and SL were performed by WT in the MN. 


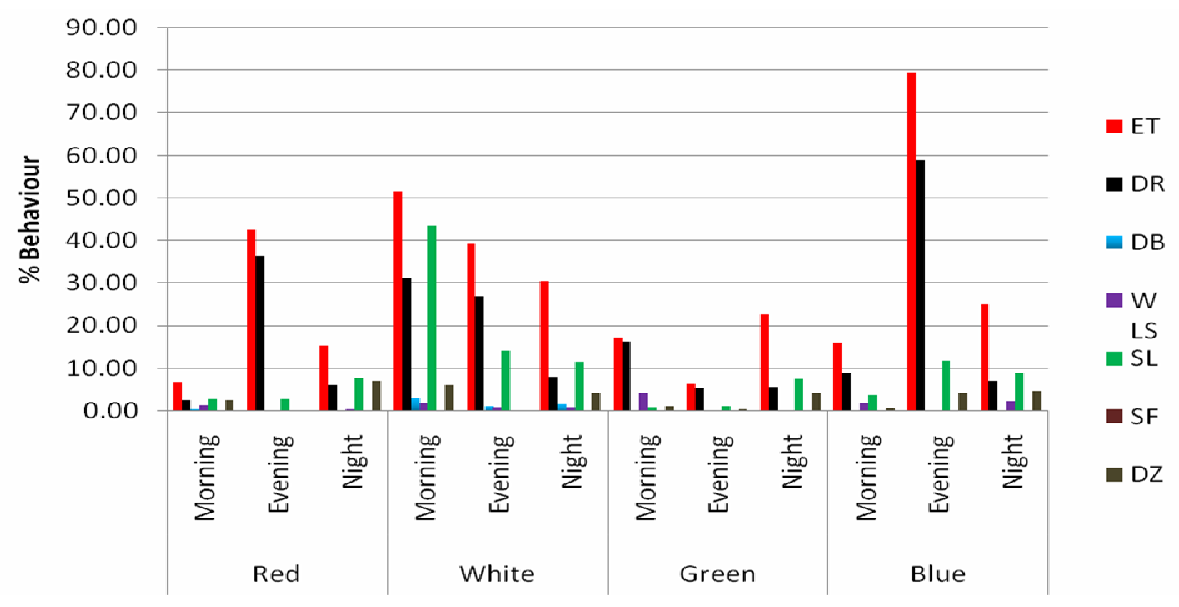

Fig. 4. Significantly different $(p<0.05)$ behaviours among different $L C$ environments during 29-35d

\section{CONCLUSIONS}

Broilers prefer RD colour light in the NT. Their sensitivity for colour lights can be expected after 21 days. RD and WT colour lights prefered more than the BL and GN. It was observed that the associated behaviours also depend on the $\mathrm{AG}$ and the SD under tropical environmental conditions .

\section{REFERENCES}

Alsam, H. and Wathes, C.M. (1991) Conjoint preferences of chicks for heat and light intensity. British Poultry Sci. 32, 899-916.

Appleby M.C, McRae H.E. and Pietz B.E. (1984) The effect of light on the choice of nests by domestic hens. App. Ani. Ethol. 11, 249-254.

Berryman, J.C., Fullerton, C. and Sluckin, W., (1971). Complexity and colour preferences in chicks of different ages. Quart. J. Exp. Psych. 23, 255-260.

Davis, N.J., Prescott, N.B., Savory, C.J. and Wathes, C.M. (1999) Preferences of growing fowls for different light intensities in relation to age, strain and behaviour. Anim. Welfare 8 , 193-203.

Kristensen, H. H., G.C. Perry, N.B. Prescott, J.Ladwig, A.K. Ersboll and C.M. Wathes (2006) Leg health and performance of broiler chickens reared in different light environments. British Poultry Sci. Volume 47(3), pp 257-263.

Manser, C.E. (1996) Effects of lighting on the welfare of domestic poultry. Anim. W elfare, $5,341-360$.

Martin, P. and Bateson, P. (1993). Measuring Behaviour: An Introductory Guide. Second Edition. Cambridge University Press, Cambridge, UK. 
Perrry, G. and Lewis, P. (1993). Light perception and behavior. pp 27-38 In: Savory C.J. and Hughes B.O. (eds) Fourth European Symposium on Poultry Welfare, Universities Federation for Animal Welfare: Potters Bar, U.K.

Prayitno, D.S. and Phillips, C.J.C (1997). Equating the perceived brightness of blue and red lights to hens. Br. Poultry Sci. 38, 136-141.

Prayitno, D.S., Phillips, C.J.C and Omed, H. (1997). The effects of colour of lighting on the behaviour and production of meat chicken. Poultry Sci. 76, 452-457.

Regolin, L. and Vallortigara, G., (1996). Lateral asymmetries during responses to novelcoloured objects in the domestic chick: a developmental study. Behav. Process. 37, 67-74.

Rogers, L.J.(1994). The molecular neurobiology of early learning, development and sensitive periods with emphasis on the avian brain. Mol. Neurobiol. 7, 161-187.

Sakai, H, Coffey, P., Villegas-Perez, M.P., Vidal-Sanz, M., Young, M.J., Lund, R.D. and Fukudu, Y. (1996). Light induced EEG desynchronization and behavioural arousal in rats with restored retinocollicular projection by peripheral nerve graft. Neuroscience Letters 218, 45-48.

SAS, (2003). The SAS System for Windows, Release 9.1.3 Service pack 2, TS-level 01M3.SAS Institute Inc., Cary, NC,USA.

Savory, C.J. and Duncan, I.J.H. (1982/83). Voluntary regulation of lighting by domestic fowl in Skinner boxes.J. Appl. Anim. Behav. Sci. 64, 47-55.

Schutz, K., Kerje, S., Carlborg, O., Jaccobson, L., Anderson, L. and Jensen, P. (2002) QTL analysis of red jungle fowl $\mathrm{x}$ white leghorn intercross reveals trade-off in resource allocation between behavior and production traits. Behaviour Genetics 32,423-433.

Senaratna, D., Samarakone, T.S., Atapattu, N.S.B.M., Paranawithana, D.R. and Chandrasiri, W.C.J (2010). Light Colour Prefernce of Broilers reared in Tropical Environment. Proc. $7^{\text {th }}$ Academic Sessions, University of Ruhuna, pg.114.

Tucker, S.S. and Charles, D.R. (1993). Light intensity, intermittent lighting and feeding regime during rearing as affecting egg production and egg quality. British Poultry Sci. 34, 255-266

Vandenberg, C. and Widowski, T.M., (2000). Hen's preferences for high intensity high pressure sodium or low-intensity incandescent lighting. J. Appl. Anim. Behav. Sci. 71, 319333.

Widowski, T.M., Keeling, L.J. and Duncan, I.J.H. (1992). The preferences of hens for compact fluorescent over incandescent lighting. Canadian J. Anim. Sci. 72, 203-211.

Widowski, T.M. and Duncan, I.J.H. (1996). Laying hens do not have a preference for high frequency verses low-frequency compact fluorescent light sources. Canadian J.Anim. Sci. $76,177-181$. 